\title{
High Altitude and Anesthesia
}

\author{
Zara Wani $^{1}$ Meenaxi Sharma ${ }^{1}$ \\ ${ }^{1}$ Department of Anaesthesiology and Critical Care, NIMS Medical \\ College, Jaipur, Rajasthan, India \\ J Card Crit Care TSS 2017;1:30-33.
}

\begin{abstract}
Address for correspondence Dr. Zara Wani, MBBS, MD, Department of Anaesthesiology and Critical Care, NIMS Medical College, Jaipur, Rajasthan, India (e-mail: zarawani14@yahoo.com).
\end{abstract}

\section{Introduction}

Anesthesia at high altitude is a challenging task for all anesthesiologists. The high-altitude intensivists are challenged by the human organism in a hypoxic environment, and the true research potentials presented by high altitude, where the body is subjected to an essentially isolated hypoxic challenge, are just beginning to be realized. One of the problems when talking about high altitude is the absence of any universally accepted definition as to what exactly constitutes "high." High altitude generally means an elevation of $3,000 \mathrm{~m}$ or more above the sea level (-Table $\mathbf{1}$ ). Although the biological effect of high altitude appears at lower levels, but at this level onward, people ascending to high mountains generally show biochemical, physical, or anatomical changes. ${ }^{1}$

\section{Physiologic Changes}

As the altitude rises, the partial pressure of the oxygen in the alveoli declines. Therefore, the arterial saturation level of the blood is lower. Physiological changes and effects that may be noted in a patient suffering from hypoxia include excitation, drowsiness, headaches, mental fatigue, lassitude, euphoria, and an increase in ventilation. The last one, which is most often seen as one of the body's compensatory mechanisms, begins at altitudes above $8,000 \mathrm{ft}$; the other mentioned physiologic changes begin at $12,000 \mathrm{ft}$. Approximately $93 \%$ or less arterial saturation is sufficient to stimulate the chemoreceptors to increase ventilation. ${ }^{2,3}$ At altitudes between 16,000 and $20,000 \mathrm{ft}$, ventilation reaches a maximum effectiveness. At altitudes above this, the chemoreceptors are not stimulated to increase ventilation any further. When there is an increase in pulmonary ventilation, a reduction in carbon alkalemia is compensated by changes in renal function. The kidneys excrete more base; therefore, the urine becomes less acid. ${ }^{2}$ It has also been studied that cerebrospinal fluid $\mathrm{pH}$ has a role in regulating ventilation at high altitudes. When hypoxia is relieved as a result of breathing increased oxygen concentrations, ventilation decreases by small amounts. The $\mathrm{PCO}_{2}$ elevates cerebrospinal fluid $\mathrm{H}^{+}$, making up most of the respiratory drive, so ventilation is only slightly depressed. ${ }^{4,5}$

\section{Cardiovascular Changes at Altitude}

It is impossible to separate the cardiovascular and respiratory systems when considering oxygen delivery to the tissues. Acute exposure to high altitude results in an increase in heart rate and cardiac output. With acclimatization, resting heart rate returns toward its sea-level value up to an altitude of around 4,500 m, but for a given level of exercise, it remains higher. The reason for this reduction in maximum heart rate
DOI https://doi.org/ $10.1055 / \mathrm{s}-0037-1604203$.
Copyright (c) 2017 Official Publication of License terms

The Simulation Society (TSS), accredited

by International Society of

Cardiovascular Ultrasound (ISCU) 
Table 1 Level of altitudes

\begin{tabular}{|l|l|}
\hline & Altitude in meters \\
\hline Baseline & $3,000 \mathrm{~m}$ above mean sea level \\
\hline Mild-high altitude & $3,000-3,600 \mathrm{~m}$ above mean sea level up to $4,200 \mathrm{~m}$ acclimatized people \\
\hline Moderate high altitude & $4,200-4,800 \mathrm{~m}$ above mean sea level \\
\hline Extreme high altitude & $4,800 \mathrm{~m}$ above mean sea level \\
\hline
\end{tabular}

is controversial. Cardiac $\beta$-receptors undergo downregulation at altitude, and it has been speculated that this functions as a protective mechanism against ischemia. However, as heart rate is higher for any given level of exercise, it is perhaps more likely that the reduction in maximum heart rate simply reflects the reduction in the maximum exercise level that occurs at high altitude. Despite the increase in heart rate for a given level of exercise, the cardiac output response in acclimatized patients remains unchanged. As heart rate is increased, this implies that stroke volume must be reduced. Pulmonary capillary wedge pressure at rest did not change from sea level but was reduced with exercise. The relationship between right atrial pressure and stroke volume was well preserved. In addition, breathing supplementary oxygen did not improve stroke volume for a given filling pressure. $^{6}$

\section{Pulmonary Circulation}

Exposure to hypobaric hypoxia produces pulmonary vasoconstriction, resulting in pulmonary hypertension proportional to the degree of hypoxia. The hypoxic pulmonary vasoconstriction (HPVC) is nonlinear and highly variable between individuals. In normal lowland responders, it com-

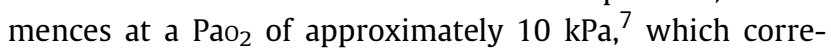
sponds to an altitude of around $2,000 \mathrm{~m}$. The pulmonary pressor response is further enhanced with exercise, with the mean pulmonary artery pressure (PAP) rising as high as 55 to $60 \mathrm{~mm} \mathrm{Hg}$ during exercise at extreme altitude. ${ }^{8}$ During acute exposure to hypoxia, breathing oxygen restores resting PAP to its sea-level values, but once acclimatization has occurred, this is no longer the case. This effect can be seen as early as 3 weeks after exposure to high altitude, ${ }^{8}$ suggesting that even after this relatively short period, structural changes are occurring in the pulmonary arteries.

\section{Cerebral Circulation and Cerebral Function}

As mentioned previously, the effect of acute hypobaric hypoxia is to increase cerebral blood flow (CBF), but the increase is limited by the concomitant reduction in $\mathrm{PaCO}_{2}$ occurring as a result of hyperventilation. A study by Severinghaus showed a 24\% increase in CBF after 6 to 12 hours of exposure to $3,810 \mathrm{~m}$ in comparison with the sea-level values, which had fallen to a $13 \%$ increase over sea level after 3 to 5 days. Similar increases were found in carotid and vertebral artery flow at $4,300 \mathrm{~m}$, which had returned to sea-level values after 4 to 12 days. $^{9}$ It is generally accepted that exposure to hypobaric hypoxia impairs cognitive function. Impairment of task learning can be demonstrated at an altitude of $2,440 \mathrm{~m}^{10}$ Acclimatization appears to give some degree of protection when compared with acute exposure; however, there is clear evidence of residual impairment of central nervous system (CNS) function after exposure to high altitude, which persists for up to at least 1 year after exposure. ${ }^{11}$

\section{Fluid and Electrolyte Changes}

The normal mechanisms of fluid homeostasis are perturbed at high altitude, and the situation is further complicated by the effect of exercise. On exposure to altitudes of 3,500 to $4,000 \mathrm{~m}$, plasma volume is reduced by 3 to $5 \mathrm{~mL} / \mathrm{kg}$. This occurs relatively rapidly after arrival at altitude, and the deficit would appear to persist for at least 3 or 4 months before starting to return toward normal. ${ }^{12}$ Total body water is reduced by around $5 \%{ }^{13}$ The decrease in total body water is probably due to decreased water intake, possibly due to alterations in thirst regulation, coupled with increased insensible losses and an inappropriately unchanged urine output. Sodium and potassium balance seems to be unchanged. Despite this reduction in body water and the resultant increase in osmolality, there is little evidence that hypoxia has any effect on antidiuretic hormone secretion, except perhaps in some cases of acute mountain sickness. ${ }^{14}$ The renin-angiotensin-aldosterone system, however, presents a more complex picture. ${ }^{15}$ Both exercise and hypoxia stimulate renin release, but aldosterone release is decreased at high altitude. Despite a reduction in angiotensin-converting enzyme (ACE) concentration, ACE activity does not appear to be affected by hypoxia.

\section{Hematology}

The rapid reduction in plasma volume on exposure to high altitude results in an increase in hemoglobin concentration. At the same time as the reduction in plasma volume, hypoxia stimulates renal and hepatic erythropoietin production stimulating erythropoiesis. The erythropoietin response is rapid, with increased concentrations being detectable only 2 hours after arrival at altitude. The response peaks at around 2 days and, if the patient remains at the same altitude, has returned to sea-level values after 3 weeks.

\section{Peripheral Tissue Changes}

Capillary density in muscle is unchanged, although the average diameter of muscle fibers appears to be reduced. 
One possible advantage of this change would be to reduce the distance that oxygen has to diffuse from the capillaries to the mitochondria. Muscle myoglobin appears to be increased at altitude improving oxygen diffusion through muscle cells and perhaps acting as an oxygen reservoir during periods of profound cellular hypoxia. ${ }^{16}$

\section{Body Temperature}

Low ambient temperature can be encountered at HA or polar region, particularly when anesthesia is to be performed at field condition. Hypothermia is defined as core body temperature less than $350^{\circ} \mathrm{C}$. Once the body temperature falls below $350^{\circ} \mathrm{C}$, the ability of hypothalamus, the temperature regulation center is lost due to depression of production of chemical heat by each cell. As temperature decreases, there is fall of blood pressure (BP), although initially there is rise in $\mathrm{BP}$ due to release of catecholamine. There is marked irritability of atrioventricular (AV) bundle leading to atrial and ventricular fibrillation. A common cause of death is ventricular fibrillation when the temperature reaches below 28 to $290^{\circ} \mathrm{C}$. Minimum alveolar concentration for inhalation anesthetic agents decreases $5 \%$ per degree Celsius fall of body temperature. This is probably due to decreased CNS activity and increased solubility of anesthetic vapors at low temperature.

\section{Anesthetic Management}

Anesthetic considerations for preoperative preparations in high altitudes must include the depressant effects of premedicating drugs.

\section{Volume Resuscitation}

Whenever indicated, it can be performed by using intravenous crystalloids, colloids, blood, or plasma. However, all intravenous fluids and blood should be warmed to body temperature before transfusion and great care should be taken not to overload the patients with fluid in view of risk of developing pulmonary edema. If heavy sedation with hypnotics, narcotics, or other drugs is necessary, oxygen should be started at the time the preoperative medication is given. ${ }^{17}$ To increase oxygen levels, nasal oxygen at 3 to $4 \mathrm{~L} / \mathrm{min}$ gives an approximate oxygen concentration of 24 to $27 \%$. Mask oxygen at 5 to $6 \mathrm{~L} / \mathrm{min}$ gives an approximate oxygen concentration of 40 to $50 \%$. When opiates are used, cyanosis and tachycardia have been observed. Opiates suppress pulmonary ventilation, which is the most important compensation for the low oxygen tension. Postanesthetic headache and nausea are common whenever pulmonary ventilation is suppressed. ${ }^{3,17,18}$ The anesthesiologist may observe an increase in bleeding for patients living at increased altitudes. Hemorrhage is a common complication. This is most likely due to the polycythemia and longer coagulation times. ${ }^{17}$ The increased blood volume, venous pressure vasodilation, and number of capillaries may explain why there is an increase in bleeding and longer coagulation times. It has been recommended that preoperative blood letting (phlebotomy) be done on patients with hemoglobin values above those considered normal at a particular altitude. Injection atropine and glycopyrrolate can be used safely for antimuscarinic effects. With increased altitudes, anesthetic agents, gases, vapors, and oxygen should be given in higher concentrations to maintain arterial partial pressures for anesthesia. Increased oxygen concentrations should also be provided with intravenous barbiturate anesthesia. Patient should be preoxygenated for 3 to 5 minutes with 100\% oxygen before induction, in high-altitude conditions. Patients who have a lowered arterial $\mathrm{Po}_{2}$ may develop hypoxia more rapidly with airway complications. Increasing the inspired oxygen concentration with nitrous oxide decreases the amnesic. In this situation, nitrous oxide is unable to achieve anesthetic partial pressures without lowering the oxygen tension to a dangerous hypoxic level. Because of decreased barometric pressures, low partial pressures interfere with nitrous oxide uptake. In Denver (5,280 ft), it is recommended that nitrous oxide be supplemented using a balanced anesthetic technique. $^{4,5,17}$ The anesthesiologist must remember that increased concentrations of this less potent anesthetic agent may decrease oxygen tensions to hypoxic levels. Therefore, the technique of oxygen and nitrous oxide anesthesia should be avoided in higher altitudes. Halothane is satisfactory agent for use in higher altitudes. They permit the use of higher concentrations of oxygen and provide rapid induction with a rapid recovery. Assisted or controlled ventilation is required even with these agents to prevent muscle fatigue and avoid hypoxia. The disadvantages of halothane are possible bradycardia and hypotension. ${ }^{4}$ Dissociative Analgesia: Supplemental oxygen may not be available in some of HA location so it is important to select an anesthetic technique that is least likely to suppress ventilation. Ketamine anesthesia is a safe anesthesia agent used at HA if monitored carefully. Spinal anesthesia is avoided whenever possible at the higher altitudes. The incidence of postspinal headache is very high for unknown reasons. Possibly, it may result from a decrease in alveolar ventilation and hypoxia or from poor hydration. The use of spinal anesthesia and its resulting side effects must be weighed against the possible benefits. It has been observed also that local anesthetics have a shorter duration in the higher altitudes. The reasons for this pharmacologic phenomenon are also unknown. With the use of muscle relaxants, deep levels of anesthesia are avoided; therefore, the risk of hypoxia and acidosis is lessened. Long-acting muscle relaxants should be used with caution to avoid prolonged muscular weakness and because specific information is not available on the use of reversal agents at higher altitudes. Altitude may also affect anesthetic equipment. Flowmeters, calibrated at sea level, deliver a higher flow than indicated due to the reduced density of gases. The error for all anesthetic gases is calculated at approximately $1 \% / 1,000 \mathrm{ft}$ up to $50,000 \mathrm{ft}$. In Denver $(5,280 \mathrm{ft}$ ), vaporizers deliver approximately $10 \%$ more agent than the flowmeter indicates (Mitten JN, Major, ANC, CRNA, MA. oral communication). Vaporizers function more efficiently at lower barometric pressures because the boiling point of volatile anesthetics is decreased; the vapor pressure constitutes a 
higher percentage of the barometric pressure at the same temperature. Therefore, vaporization is easier and concentrations will be greater. Environmental conditions may be such that volatile agents may boil inside vaporizers in a warm room. At $15,000 \mathrm{ft}$, the boiling point of halothane is $\mathbf{9 5}^{\circ} \mathbf{F}$. This in-circuit vapor, in the Vernitrol vaporizer or copper kettle, may be delivered to the patient even if the oxygen flowmeter through the vaporizer is turned off. Halothane is vaporized by the fact of its boiling at $95^{\circ} \mathrm{F}$ at $15,000 \mathrm{ft}$ without oxygen vaporization. It is carried by the inflow of fresh gases by the flowmeter. Postoperatively, it is recommended that oxygen be given for a minimum of 1 hour. All patients in increased altitudes require pre- and postoperative oxygen therapy. If inadequate ventilation is noted during the postoperative period, controlled or assisted ventilation should be continued until the patient is alert and muscle power is recovered.

\section{Conclusion}

In summary, the anesthesiologist working at increased altitudes must consider the physical and physiological effects of low barometric pressures, decreased oxygen tensions, and physiological changes of the acclimatized and unacclimnatized resident. Also to be considered are the changes that occur with volatile agents, adjunct drugs, and anesthetic equipment. The anesthesiologist should avoid drugs that have a prolonged depressing effect on the respiratory center. A smooth, rapid induction with tracheal intubation is recommended. Agent such as halothane is used primarily because it allows increased oxygen concentrations.

Short-acting muscle relaxants are used to control alveolar ventilation, and thus they avoid hypoxia. Spinal anesthesia is thought to decrease alveolar ventilation, resulting in hypoxia. This decrease is thought to increase the incidence of postspinal headache, but this has not been proven.

\section{References}

1 DGAFMS Medical Memorandum No 60. Anaesthesia at High Altitude; 1993

2 Wylic WD, Churchill-Davidson HC. A Practice of Anesthesia. 3rd ed. Chicago, IL: Year Book; 1972
3 Guyton AC. 1976. Textbook of Medical Physiology. 6th ed. Philadelphia, PA: W.B. Saunders; 1976

4 Severinghaus JW, Mitchell RA, Richardson BW, Singer MM. Respiratory control at high altitude suggesting active transport regulation of CSF ph. J Appl Physiol 1963;18:1155-1166

5 Severinghaus JW, Carcelen A. Cerebrospinal fluid in man native to high altitude. J Appl Physiol 1964;19:319-321

6 Reeves JT, Groves BM, Sutton JR, et al. Operation Everest II: preservation of cardiac function at extreme altitude. J Appl Physiol (1985) 1987;63(02):531-539

7 Marshall BE, Marshall C, Frasch F, Hanson CW. Role of hypoxic pulmonary vasoconstriction in pulmonary gas exchange and blood flow distribution. 1. Physiologic concepts. Intensive Care Med 1994;20(04):291-297

8 Groves BM, Reeves JT, Sutton JR, et al. Operation Everest II: elevated high-altitude pulmonary resistance unresponsive to oxygen. J Appl Physiol (1985) 1987;63(02):521-530

9 Huang SY, Moore LG, McCullough RE, et al. Internal carotid and vertebral arterial flow velocity in men at high altitude. J Appl Physiol (1985) 1987;63(01):395-400

10 Farmer EW, Lupa HT, Dunlop F, McGowan JF. Task learning under mild hypoxia. In: Sutton JR, Coates G, Houston CS, eds. Hypoxia and Mountain Medicine. Burlington, VT: Queen City Printers; 1992:1-8

11 Hornbein TF, Townes BD, Schoene RB, Sutton JR, Houston CS. The cost to the central nervous system of climbing to extremely high altitude. N Engl J Med 1989;321(25):1714-1719

12 Pugh LGCE. Blood volume and haemoglobin concentration at altitudes above $18000 \mathrm{ft}(5500 \mathrm{~m})$. J Physiol 1964;170: 344-354

13 Fusch C, Gfrörer W, Koch C, Thomas A, Grünert A, Moeller H. Water turnover and body composition during long-term exposure to high altitude (4,900-7,600 m). J Appl Physiol (1985) 1996;80(04): $1118-1125$

14 Claybaugh JR, Wade CE, Sato AK, Cucinell SA, Lane JC, Maher JT. Antidiuretic hormone responses to eucapnic and hypocapnic hypoxia in humans. J Appl Physiol 1982;53(04):815-823

15 Olsen NV. Effect of hypoxaemia on water and sodium homeostatic hormones and renal function. Acta Anaesthesiol Scand Suppl 1995;107(Suppl):165-170

16 Ward MP, Milledge JS, West JB. High Altitude Medicine and Physiology. 2nd ed. London, UK: Chapman \& Hall Medical; 1995:197-216

17 Safar P, Tenicela R. High altitude physiology in relation to anesthesia and inhalation therapy. Anesthesiology 1964I; 25:515-531

18 Collins VJ. Principles of Anesthesiology. 2nd ed. Philadelphia, PA: Henry Kimpton; 1976 